\title{
CEMITÉRIOS: FONTES POTENCIAIS DE IMPACTOS AMBIENTAIS
}

Rosiane Bacigalupo Estudante do Curso de Geografia da Universidade do Estado do Rio de Janeiro rosianebauer@hotmail.com

\section{INTRODUÇÃO}

Após o óbito o corpo humano se transforma, constituindo um ecossistema de populações formado, sobretudo, por artrópodes, bactérias, microorganismos patogênicos e destruidores de matéria orgânica. A transformação do corpo humano e a sua decomposição ocorridas em lugares onde não há estudos hidrogeológicos e infraestrutura adequada, pode vir a causar significativos impactos físicos sobre o ambiente, sobretudo a contaminação das águas superficiais e subterrâneas por microorganismos que se proliferam ao se decomporem os corpos.

As necrópoles constituem um causador potencial de degradação ambiental. Quando mal conservadas seus efeitos podem ser percebidos a partir de emanação dos gases funerários, ocasionando um mau cheiro; exposição de sepulturas mal conservadas a águas da chuva, propiciando a enchente destas, podendo ocasionar o processo de saponificação dos corpos e ainda o escoamento das águas que entram em contatos com estas sepulturas em direção a alguma comunidade ou lugar que pode vir a trazer graves riscos à saúde da população que reside ao entorno da necrópole.

O estudo da contaminação proveniente das atividades cemiteriais embora exista, são de fato, muito pouco abordados não apenas pela mídia, mas também pela comunidade científica como um todo. Tal fato vem muito a implicar na carência de informações e dados para que pesquisas referentes à temática sejam abordadas. 


\section{BREVE HISTÓRICO}

A palavra cemitério, originária do grego koumeterian e do latim coemeteriun, significa dormitório, lugar onde se dorme, recinto onde se enterram ou se guardam os mortos e tem como sinônimos as palavras necrópole, carneiro, sepulcrário, campo-santo, cidade dos pés juntos e última moradia. (CAMPOS, 2007)

O processo de enterramento e sepultamento dos corpos não é um advento de pouco tempo na história, de acordo com o professor Alberto Pacheco da Universidade de São Paulo, "o sepultamento ou enterramento de corpos humano parece remontar a 100 mil anos antes de nossa era. A partir dos 10 mil anos a.C, as sepulturas são agrupadas e, assim, aparecem os primeiros cemitérios com túmulos individuais e sepulturas coletivas (PACHECO).

O cristianismo fora o grande marco no processo de sepultamento coletivo dos corpos humano, pois fora a partir deste a disseminação do ideal de descanso para os mortos a espera do juízo final. De acordo com Alberto Pacheco, "só é possível falar em cemitérios a partir da Idade Média Europeia, quando se enterravam os mortos nas igrejas, paróquias, abadias, mosteiros, colégios, seminários e hospitais." (PACHECO).

Ainda na idade Média, é sabido, que por questões higiênicas os cemitérios passaram a ser localizados em lugares afastados das áreas urbanas.

Cabe ainda salientar, que os cemitérios sempre tiveram como finalidade de ser um memorial onde seja possível guardar à memória dos entes falecidos. Talvez esta seja umas das principais razões que implicam no fato desses ambientes terem durante anos ficados a margens de estudos científicos, o que hoje implica numa carência de referências bibliográficas sobre os mesmos. No entanto, os estudos referentes a esta temática é de destacada importância para a sociedade, pois reflete em muitas das vezes em estar pondo em risco a vida de pessoas vivas que residem próximo a esses locais, além de estar contribuindo para o impacto ambiental do meio físico. 


\section{CEMITÉRIOS, MEIO AMBIENTE E SAÚDE PÚBLICA.}

Um dos grandes dilemas da atualidade, debatidos em diferentes encontros expostos a todo o momento pela mídia é a necessidade de conservar diversos recursos naturais a fim de assegurá-lo para as gerações futuras; Fazendo um uso sustentável destes. Dentre diversas formas de poluição e contaminação que podem ser o agente agressor ao meio ambiente, neste trabalho será destacada a poluição que tem como agente causador o necrochorume, liquido proveniente do processo de decomposição dos corpos, proveniente da atividade cemiterial.

De acordo como o professor Alberto Pacheco, "os cemitérios são um risco potencial para o ambiente." Logo, esse problema vem se agravar em virtude de que a maioria dos cemitérios foram construídos em lugares que apresentam valor imobiliário baixo sem quaisquer uso de estudos geotécnicos prévios. O não estudo das condições geológicas e hidrogeológicas podem vir ainda mais a contribuir para a exposição da população residente nas proximidades das necrópoles aos riscos provenientes da atividade cemitérial.

Ainda vivo o ser humano vive em estado de equilíbrio como o seu meio, no entanto após o seu falecimento, seu corpo tende a iniciar o processo de putrefação, sendo esta a destruição dos tecidos do corpo por enzimas e bactérias. Passando assim pelo que conhecemos como fenômenos transformadores destrutivos, no entanto, cada fenômeno ou estágio estando sujeito a durabilidades diferentes em virtude das variações peculiares de acordo com as diversas condições ambientais.

Após o óbito, cada corpo decomposto libera em torno de 30 a 40 litros de necrochorume, neologismo conhecido técnica e cientificamente por produto da coliqüação, criado por analogia ao chorume dos resíduos orgânicos dos aterros. É possível definir o nechochorume como uma solução viscosa, composta em sua maior parte por água, rico em sais minerais e substâncias orgânicas degradáveis, sua formação se dá em virtude do processo de decomposição dos cadáveres. 
O necrochorume é o principal responsável pela poluição ambiental causada pelos cemitérios. Nele pode conter quantidades elevadas de diferentes tipos de bactérias e muitos tipos de vírus causadores de doenças que podem ser veiculadas hidricamente.

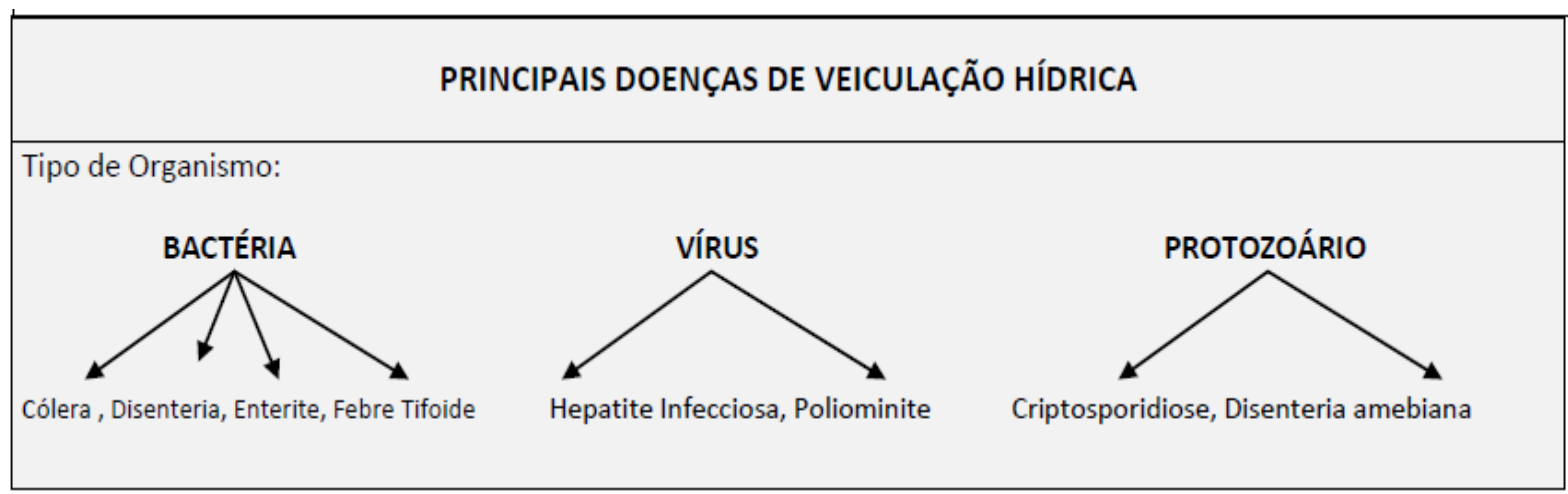

Tabela 1: A composição do Necrochorume, 2011. Fonte: Arquivo da autora

Dentre as muitas características do necrochorume, cabe salientar:

- Cor acinzentada ou acastanhada;

- Viscosidade maior que a água;

- Odor forte;

- Densidade média de $1,23 \mathrm{~g} / \mathrm{cm}^{3}$

\section{Composição do Necrochorume}

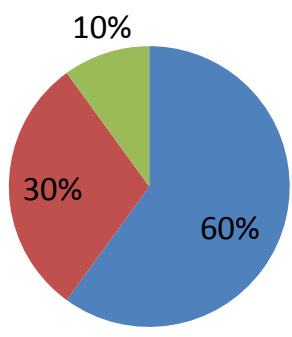

Água

Sais Minerais

- Substâncias Orgânicas

Degradáveis

Gráfico 1: A composição do Necrochorume, 2011. Fonte: Arquivo da autora

Em virtude da densidade do necrochorume em relação à água, há a formação de plumas de contaminação, que podem vir a disseminar-se no solo; Dependendo, sobretudo, de sua formação geológica e seguindo o fluxo subterrâneo. Como pode ser exemplificado na imagem abaixo. 


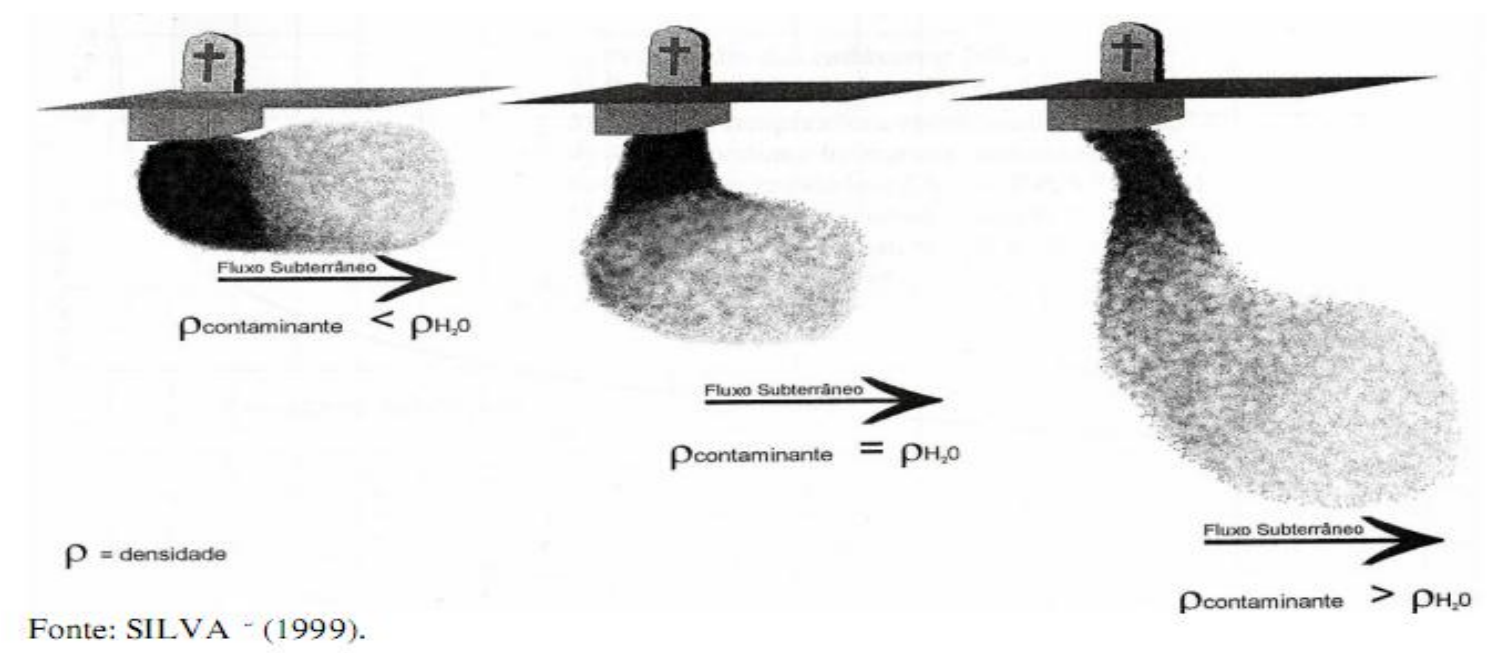

Imagem 1: Esquema de formação de plumas de contaminação. Fonte:

CAMPOS, 2007.

A penetração do necrochorume no subsolo poder vir a implicar na contaminação das águas subterrâneas e superficiais, quando estas entram em contato com o processo de decomposição dos cadáveres. A contaminação por materiais originados das atividades cemiteriais as águas subterrâneas e superficiais podem ocorrer, segundo MEGLIORINI (1994) "por causa da existência de artrópodes, microorganismos patogênicos e destruidores de matéria orgânica, bactérias, vírus e substâncias químicas liberadas.

Podendo o necrochorume alcançar as águas subterrâneas e estas vindas a serem captadas por poços feitos pela população que residem ao entorno dos cemitérios, estas estarão sujeitas a vários riscos de saúde. A água é vital para toda a vida existente no planeta. Os humanos não podem sobreviver mais do que poucos dias sem ela, e a qualidade desta é importante para que seja garantida a manutenção da saúde humana. De acordo com CAMPOS (2007) "as doenças de veiculação hídrica são doenças em que a água é o agente infeccioso, ou seja, os microorganismos patogênicos que atingem a água por intermédio de excretas de pessoas ou de animais infectados." De acordo com PACHECO (2007) " pessoas que morrem de doenças infecto-contagiosas, para além de outros microorganismos, podem estar presentes no necrochorume os patogênicos, com bactérias e vírus, agentes transmissores de doenças responsáveis pela causa mortis. 
A água subterrânea forma-se quando as gotas de chuva se infiltram no solo e em outros materiais superficiais não-consolidados, penetrando até mesmo em rachaduras e fendas do substrato rochoso. Ela é extraída pela perfuração de poços e bombeamentos para a superfície. PARA ENTENDER A TERRA (2006, Pág. 320)

Os mais variados tipos de microorganismos patogênicos podem está presentes no necrochorume, e ao entrarem em contato com as águas subterrâneas podem vir a comprometer a qualidade da mesma contaminando-a com os mais variados tipos de microorganismos.

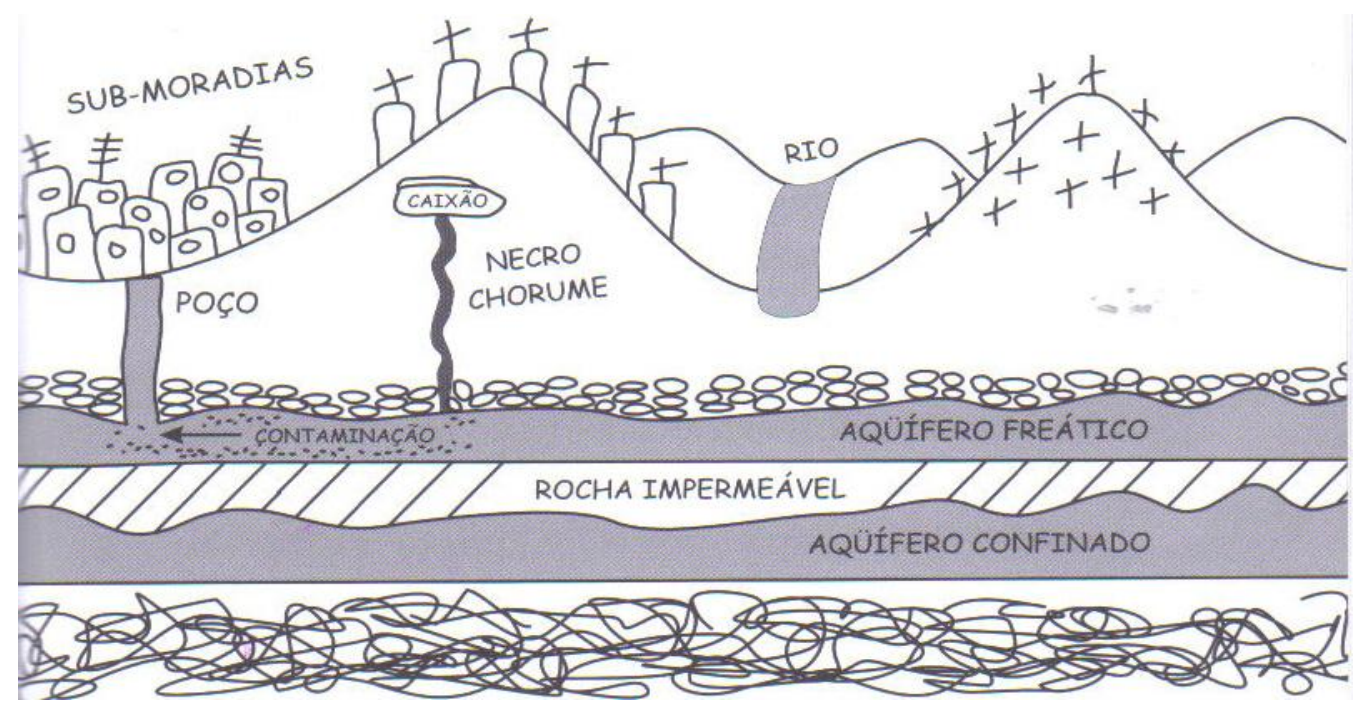

Imagem 2: Esquema de contaminação do aquífero freático pelo necrochorume, ANDRADE, 2007.

Esta água contaminada envolve, assim, questões diretamente relacionadas à saúde pública; Visto que, poder vir a comprometer a saúde da população de reside em torno das necrópoles com os mais variados tipos de doenças. Para isso é de demasiada importância os diagnósticos ambientais feito de modo multidisciplinar estudando em conjunto a Geografia e as disciplinas que perpassam a área da saúde, a fim de conhecer mecanismos de funcionamento dos mais diversos ambientes e doença, para de modo preventivo, seja possível, prevenir a questão da saúde que envolve áreas ao entorno das necrópoles. 


\section{O PROBLEMA AMBIENTAL E A LEGISLAÇÃO ESPECÍFICA NO BRASIL}

Os sepultamentos de cadáveres são, de fato, fontes de poluição para o meio ambiente, e por isso deve ser considerado como causadora de impactos ambientais. E é de suma importância que para a implantação de novos e 0 contínuo funcionamento dos cemitérios já existentes, sejam elaborados estudam geológicos e hidrogeológicos que venham minimizar e evitar futuros locais de contaminação pela atividade cemiterial.

Até o ano e 2003, mais precisamente Maio de 2003, o Brasil não tinha qualquer dispositivo legal federal sobre cemitérios. No Conselho Nacional do Meio Ambiente (Conama), foi promulgada a Resolução no 335 que dispõe sobre o licenciamento ambiental de cemitérios ambientais e verticais. A resolução estabeleceu critérios mínimos para a implantação de novos cemitérios, tais medidas foram tomadas a fim de garantir a decomposição normal dos corpos e proteger os lenções freáticos da infiltração do necrochorume. A resolução ainda deu prazo de 180 dias para que os cemitérios já existentes se adequassem às novas normas.

\section{REFERÊNCIA BIBLIOGRÁFICA}

ALMEIDA A. e MACÊDO J. Parâmetros físico-químicos de caracterização da contaminação do lençol freático por necrochorume. In Seminário de Gestão Ambiental - Um convite à interdisciplinaridade. Juiz de Fora - MG; 2005.

BARBOSA MC, COELHO H. Impacto Ambiental dos cemitérios horizontais e sua relação com o controle sanitário das áreas urbanas. Disponível em: http/www.biosegurancahospitalar.com.br/files/ImAmbCem.doc.

CAMPOS A. Avaliação do Potencial de poluição dos solos e nas águas subterrâneas decorrente da atividade cemiterial. São Paulo; 2007. 
FELICIONE F.; ANDRADE F A. e BORTOLOZZO N.; A ameaça dos mortos: cemitérios põem em risco a qualidade das águas subterrâneas. São Paulo; 2007.

PACHECO A. Cemitério e Meio Ambiente [tema de livre docência]. São Paulo Instituto de Geociências da USP; 2000.

PACHECO A. Os cemitérios como risco potencial para as águas de abastecimento. Revista Sistema de Planejamento para a Administração Metropolitana, ano 4, n. 17, 1986.

PACHECO CEM, MARINHOS LW, STRACERI LYA, SHATKOVSKY M, IRIYA AS, COLUCCI R, KINOSHITA RK. Programa de minimização de contaminação das águas subterrâneas causadas por cemitérios [trabalho de curso de especialização] São Paulo, Faculdade de Saúde Pública da USP, 1993.

PAGANINI WS. Introdução ao controle de poluição de águas. In Controle da Poluição do Meio Poluição das Águas. São Paulo; 2006.

PIRES AS. São os Cemitérios a melhor solução para a destinação dos Mortos? In IV Encontro Nacional da Anppas. Brasília-DF; 2008.

PRESS F.; SIEVER, R.; GROTZINGER, J. e JORDAN, T.H. Para Entender a Terra, Tradutor e Coordenador. Rualdo Menegat. Ed. Bookman. Porto Alegre, RS; (2006).

ROSS JL. Geomorfologia, Ambiente e Planejamento, São Paulo; 2008. 